\title{
Drive for Muscularity in Lithuanian Male Students: Psychometrics and Associated Characteristics
}

\author{
Miglẻ Bacevičienė, Žavinta Titenytė, Vaiva Balčiūnienė, Rasa Jankauskienė \\ Lithuanian Sports University, Kaunas, Lithuania
}

\begin{abstract}
Background. The drive for muscularity in men is associated with a negative body image, psychosocial, and physiological outcomes. The aim of the present study was to test the psychometric properties of the Lithuanian version of the Drive for Muscularity Scale (DMS-LT) and associated characteristics in the sample of young adults (men).

Methods. The sample consisted of 763 male students. The ages ranged from 18 to 32 years, with a mean age of $20.4(S D=3.1)$. Participants completed the Lithuanian translation of DMS-LT alongside with the measures of disordered eating, sociocultural attitudes towards appearance questionnaire, body mass index, self-esteem, and participation in sports.

Results. The instrument showed good internal consistency (Cronbach's alpha $=.92)$ and test-retest reliability $(I C C=.87)$. The two-dimensional factor structure of the proposed original scale was not confirmed. DMS-LT was negatively correlated with self-esteem. Positive associations were observed between DMS-LT, muscular/athletic body ideal internalization, and disordered eating. Drive for muscularity attitudes and behaviors were more expressed in male students attending sports clubs.

Conclusions. The results of the present study support the psychometric properties of the DMS-LT and its' use in Lithuanian samples of young men. The instrument might also be used in clinical practice. It is important to develop prevention programs that decrease body image concerns and prevent disordered eating in young men.
\end{abstract}

Keywords: drive for muscularity, body image, psychometric properties of the scale, students.

\section{INTRODUCTION}

B ody image concerns and disordered eating behaviors have been historically more extensively studied in women compared to men. Nevertheless, existing findings suggest that a significant part of men suffer from body image concerns and dysfunctional behaviors (Gomes, Simães, Dias, Almeida, \& Gonçalves, 2019; Tylka, 2011). Research has demonstrated that girls and women are pressured to attain the thin ideal and strive for thinness (Cruz-Sáez, Pascual, Salaberria, Etxebarria, \& Echeburúa, 2015). However, boys and men experience societal pressure to achieve the muscular mesomorphic body shape, and this behavior is leading to the drive for muscularity (McCreary, Sasse, Saucier, \& Dorsch, 2004).
Further, studies have demonstrated that sociocultural pressures mediated by social comparisons and internalization of muscular and low-fat body ideals are associated with men's body dissatisfaction and drive for muscularity, which in turn might lead to the disordered eating (Tylka, 2011).

The drive for muscularity is an individual's motivation to become more muscular (McCreary et al., 2004). Research has demonstrated that drive for muscularity is associated with the psychological distress, depressive symptoms (DeBlaere \& Brewster, 2017; Eik-Nes, Austin, Blashill, Murray, \& Calzo, 2018), internalized shame (Larison \& Pritchard, 2019), neurotism (Benford \& Swami, 2014), low self-esteem (Sepulveda, Parks, de 
Pellegrin, Anastasiadou, \& Blanco, 2016; Swami, Barron, Lau, \& Jaafar, 2016), internalization of the muscular ideals (Stratton, Donovan, Bramwell, \& Loxton, 2015a), muscularity dissatisfaction (Chaba, d'Arripe-Longueville, Lentillon-Kaestner, \& Scoffier-Mériaux, 2018; Liu, Chang, Gill, Wu, \& Lu, 2019), difficulties in emotional regulation (Sepulveda et al., 2016), dieting and use of muscle building products (Eik-Nes et al., 2018), disordered eating (Arellano-Pérez, Vázquez-Cervantes, Fernández Cortés, \& Saucedo-Molina, 2019; Bratland-Sanda \& Sundgot-Borgen, 2012; Gomes et al., 2019; Lavender, Brown, \& Murray, 2017; Liu et al., 2019), binge drinking (Eik-Nes et al., 2018) and greater hours participating in gyms (Keum, Wong, DeBlaere, \& Brewster, 2015). The drive for muscularity scale (McCreary et al., 2004) is one of the main psychometrically sound measures for the exploration of the athletic/muscular - related body image (Kling et al., 2019). This instrument was translated into various languages demonstrating good psychometric properties. The drive for muscularity scale was validated in the samples of Asian American (Keum et al., 2015), Scottish (McPherson, McCarthy, McCreary, \& McMillan, 2010), Malay (Swami et al., 2016), Romanian (Swami, Vintila, Tudorel, Goian, \& Barron, 2018), Argentinian (Compte, Sepúlveda, de Pellegrin, \& Blanco, 2015), Mexican (Escoto et al., 2013), French (Chaba et al., 2018), Italian (Nerini, Matera, Baroni, \& Stefanile, 2016), Spanish (Sepulveda et al., 2016) samples of men. The majority of studies demonstrated good psychometric properties of the instrument (Kling, Kwakkenbos, Diedrichs, Rumsey, Frisén, et al., 2019 a).

Men's body image and the drive for muscularity is highly understudied in Eastern Europe samples of men of different ages. Unfortunately, the drive for muscularity scale is not validated in Lithuanian samples. The decreasing body image concerns and promotion of the positive body image is one of the essential purposes of disordered eating prevention and healthy lifestyle - promotion-related programs for men and women. Therefore, it is important to have a valid instrument to measure the effectiveness of these programs, especially in men. Further, the validation of the drive for muscularity scale will let to facilitate future research of the men's body image in Lithuania. Having a reliable instrument might help in clinical practice as well.

Recent meta-analyses concluded that physical activity is positively related to body image among men and boys (Bassett-Gunter, McEwan, \& Kamarhie, 2017). However, the role of the drive for muscularity in the formation of the body image in sport involved men is not clear. Some research provided evidence that participation in some kinds of sports activities (i.e., gyms) are related with the higher drive for muscularity in men (Keum et al., 2015) and participation in moderate physical activity is associated with the greater drive for muscularity in adolescents (Arellano-Pérez et al., 2019). However, there is a lack of studies on this issue, and in the present study, we wanted to provide more scientific knowledge on this topic.

Thus, the first aim of the present study was to test the psychometric properties of the drive for muscularity scale in the sample of young adults in Lithuania. We expected to replicate the original structure of the scale. Further, we aimed to evaluate the convergent validity of the instrument using measures of BMI, self-esteem, disordered eating behaviors, and internalization of the muscular/ athletic body ideal. Based on the previous studies, we expected that the drive for muscularity scale scores would be positively associated with the BMI, internalization of the muscular/athletic body image, disordered eating, and negatively - with selfesteem. Finally, we aimed to test the associations between the drive for muscularity and participation in sports. Based on the previous inconclusive findings, we did not state any hypothesis about the associations between participation in sports clubs and the drive for muscularity.

\section{METHODS}

Participants. Male students from different Lithuanian state universities and colleges participated in this study. The sample consisted of 763 male students who were enrolled in the areas of natural and agricultural (6.2\%), humanities and social $(13.0 \%)$, medical and health $(20.6 \%)$, and technology (59.2\%) sciences. Eight students (1\%) did not provide information about their study areas. The mean age of the sample was $20.4(S D=3.1)$ and ranged from 18 to 32 years.

Procedures. Eleven universities and four colleges participated in this study. As part of a more extensive study, the students completed self-report online questionnaires measuring the drive for muscularity, sociocultural influences on body image, disordered eating behaviors, selfesteem, and body mass index (BMI). The students 
completed the battery of questionnaires during scheduled class time, with no time limit. The final study sample of 763 participants with provided complete information was confirmed for statistical analysis.

Ethical considerations. The researchers received ethical approval to conduct this study by the Committee for Social Sciences Research Ethics of the Lithuanian Sports University (protocol No. SMTEK-7, 13-03-2019). Following the fundamental ethical and legal principles of the research, the students were introduced to the purpose of the study before the questionnaires were presented. The laws of anonymity, goodwill, and volunteering were followed during the survey. To avoid violating national and EU legislation, the students were instructed to mark the response "I agree to participate" or "I disagree to participate" to give their consent to participate in the study before beginning the survey.

Measures. Demographic data. Participants in the study were asked to specify their gender, age, education at university or college, and study program.

Body mass index (BMI) was based on the selfreported data of the students' height and weight from which BMI was calculated $\left(\mathrm{kg} / \mathrm{m}^{2}\right)$. For sample characteristics, as recommended by the World Health Organization classification, the students' BMI was classified into four body mass categories: underweight $\left(\mathrm{BMI}<18.5 \mathrm{~kg} / \mathrm{m}^{2}\right.$ ), normal weight $\left(\mathrm{BMI}=18.5-24.9 \mathrm{~kg} / \mathrm{m}^{2}\right)$, overweight $(\mathrm{BMI}=25.0$ $29.9 \mathrm{~kg} / \mathrm{m}^{2}$ ) and obese $\left(\mathrm{BMI} \geq 30.0 \mathrm{~kg} / \mathrm{m}^{2}\right.$ ) (World Health Organization, 1997). Distribution of body mass indexes is presented in Table 1. Average BMI in male students was $23.4(S D=3.6)$ and ranged from 15.3 to 47.3 .

The Sociocultural Attitudes Towards Appearance Questionnaire-4 (SATAQ-4) (Schaefer et al., 2015) is a 22-item self-report instrument and provides an assessment of the general role of sociocultural influences on body image and appearance-related internalization. The SATAQ-4 comprises five subscales, each of them is composed of items that are rated on a 5-point Likert scale, where 1 means definite disagreement and 5 means definite agreement. The higher the score, the greater is the acceptance or internalization of the dominant sociocultural standards for appearance. In this study only the internalization of muscular/ athletic image subscale was used. It figures out how much one believes he should look muscular and athletic. The Lithuanian version of the SATAQ-4 has demonstrated good validity and reliability in a student population sample (Baceviciene, Jankauskiene, \& Balciuniene, 2020). In the present male sample, Cronbach's alpha for the SATAQ-4 Muscular/Athletic subscale was .88 .

The Lithuanian version of the Eating Disorder Examination Questionnaire 6.0 (EDE-Q 6.0) (Fairburn \& Beglin, 1994) is a 28 -item self-report questionnaire and provides a comprehensive evaluation of the essential behavioral characteristics of EDs and eating disordered behavior. The EDE-Q 6.0 concentrates on the last 28 days and establishes two models of data. First, the six open-ended questions result in frequency data on the essential behavioral characteristics of EDs number of episodes of the behavior or number of days on which the action has occurred): objective binge eating, self-induced vomiting, laxative use, and excessive exercise. Second, 22 attitudinal questions comprise four subscales and result in subscale scores that reflect the severity of the ED characteristics. The answer options are arranged on a 7-point Likert scale from 0 (no day) to 6 (every day). A higher score reflects either greater severity or frequency. The Lithuanian version of the EDE-Q 6.0 (LT-EDE-Q 6.0) has demonstrated good validity and reliability in a student population sample (Baceviciene, Balciuniene, \& Jankauskiene, 2020). In the present study, Cronbach's alpha for the LT-EDE-Q 6.0 general was good .92.

We used Drive for Muscularity Scale, DMS (McCreary et al., 2004) to examine individual's behaviours reflecting a preoccupation with muscularity. The scale assesses an individual's perception that he or she is not muscular enough and that bulk should be added to his or her body frame, in the form of muscle mass (irrespective of a person's percentage of actual muscle mass or body fat). The subscale consists of 15 items rated on a 6-point scale ranging from 1 (never) to 6 (always) with higher scores indicating a higher drive for muscularity. Two lower-order factors can be scored: Muscularity - oriented body image attitudes and Muscularity - oriented body image behaviours. The translation of the scale into Lithuanian was carefully performed by a professional translator and then back-translated to English by two professional translators from a translation agency in Kaunas, Lithuania. The original version and developed 
translation were reviewed by translators and the final version of the translation was approved. The face validity was rated as good. For the present study, the internal consistency of the general scale was good (Cronbach $\alpha=.92$ ).

The Lithuanian version of M. Rosenberg's SelfEsteem Scale (RSES) (Rosenberg, 1979) was used to assess self-esteem and general feelings of selfworth. The scale is composed of 10 items scored on a 4-point Likert scale ranging from 1 (strongly disagree) to 4 (strongly agree). A higher score denotes a greater level of self-esteem. RSES is the most widely used measure of global self-esteem. The tool demonstrated good internal consistency in the present study. Cronbach's alpha for the RSES was .88 .

Single question was used to assess leisure-time sports club attending with the response options "yes" and "no".

Statistical analysis. First, descriptive statistics of the sample were performed, and the results are presented as the means and standard deviations and as percentages according to the type of variable. Cronbach's alpha coefficients were used for the evaluation of internal consistency. Test-retest reliability was assessed by the intraclass correlation coefficient (ICC). A score of $\geq .90$ was considered excellent. Pearson's correlation coefficients were used for the analyses of construct validity (interitem correlations). Correlations of the value $<.40$ were considered as weak, $.40-.59$ as moderate, and $\geq .6$ as strong. Third, to confirm the concurrent validity, Pearson's correlation coefficients were used to evaluate the relationships between the LT-DMS scores and the measures from the LT-EDEQ-6.0, LT-SATAQ-4 Muscular/Athletic subscale, Rosenberg's self-esteem score, and the BMI. Multiple linear regression analysis was performed to predict disordered eating behaviours, where the drive for muscularity, self-esteem, muscular/ athletic body ideal internalization, and body mass index were entered as independent variables. Next, the construct validity of the LT-DMS was studied performing confirmatory factor analysis (CFA). The goodness of fit of the model was assessed using acceptable fit values: the comparative fit index, CFI $(.90<\mathrm{CFI}<.95)$, and the root of the mean square error of approximation (RMSEA) $(0.05<$ RMSEA < 0.08). The statistical analyses were carried out using IBM SPSS Statistics 26 (IBM Corp., Armonk, NY, USA) and AMOS version 26 (IBM Corp., Armonk, NY, USA).

\section{RESULTS}

The sample characteristics are presented in Table 1. The majority of the sample was studying in the area of technology sciences (59.2\%) and in the first cycle studies (96.9\%); $26.3 \%$ of the students were employed, and $37.0 \%$ of them were attending sports clubs during their leisure time. The majority of the study participants were of normal body mass index $(n=70.2 \%)$.
Table 1. Sample characteristics (Lithuanian male students, $N=763$ )

\begin{tabular}{|c|c|c|c|}
\hline \multicolumn{2}{|c|}{ Characteristics } & $n$ & $\%$ \\
\hline \multirow{5}{*}{ Study area } & Natural / Agricultural & 47 & 6.2 \\
\hline & Social / Humanities & 99 & 13.0 \\
\hline & Medical / Health & 157 & 20.6 \\
\hline & Technology & 452 & 59.2 \\
\hline & Not specified & 8 & 1.0 \\
\hline \multirow{2}{*}{ Cycle } & Bachelors & 739 & 96.9 \\
\hline & Masters & 24 & 3.1 \\
\hline \multirow{4}{*}{ Body mass index } & Underweight & 30 & 3.9 \\
\hline & Normal weight & 536 & 70.2 \\
\hline & Overweight & 167 & 21.9 \\
\hline & Obesity & 30 & 3.9 \\
\hline \multicolumn{2}{|c|}{ Attending sports club } & 282 & 37.0 \\
\hline
\end{tabular}


Drive for muscularity scale demonstrated good internal consistency: Cronbach's alpha was .92 , inter-item correlations .45 and excellent testretest reliability $(I C C=.87)$. Confirmatory factor analysis did not confirm the suggested 2-factor structure (muscular oriented body attitudes and behaviours) and the model fit indices were poor $(G F I=.79 ; A G F I=.72 ; T L I=.81 ; C F I=.84$, RMSEA = .14). Thus, the average of the total scale was used in further analyses. Drive for muscularity positively correlated with disordered eating behaviours and muscular/athletic body ideal internalization (Table 2). A negative but not significant correlation was observed between the drive for muscularity and self-esteem.

No differences were found in the drive for muscularity scoring across different BMI groups of underweight, normal weight, and overweight/ obesity (Table 3). Students attending sports clubs demonstrated a higher drive for muscularity.

Further, multiple regression analyses were performed with the other study variables as the predictive and drive for muscularity score as the criterion variable (Table 4). Results revealed that the model was significant, explaining $25.9 \%$ of the variance of disordered eating behaviours. Variance inflation factors (VIFs) ranged from 1.0 to 1.2 indicating acceptable indices of multicollinearity. Results of the linear regression showed that a higher level of drive for muscularity, muscular body internalization, and body mass index were associated with increased risk of disordered eating behaviours. On the contrary, higher level of selfesteem was found to be as protective factor against disordered eating in men.

Table 2. Correlations between Lithuanian Drive for Muscularity scale and other study variables in Lithuanian male students $(\boldsymbol{N}=763)$

\begin{tabular}{|l|c|c|c|c|c|c|}
\hline \multicolumn{1}{|c|}{ Scales } & $\alpha$ & (1) & (2) & (3) & (4) & (5) \\
\hline (1) LT-DMS & .92 & 1.0 & & & & \\
\hline (2) LT-EDEQ-6 & .91 & $.21^{*}$ & 1.0 & & & \\
\hline (3) LT-SATAQ-4-Internalization Muscular & .90 & $.38^{*}$ & $.28^{*}$ & 1.0 & & \\
\hline (4) Self-esteem & .88 & $-.15^{*}$ & $-.18^{*}$ & .01 & 1.0 & \\
\hline (5) Body mass index & - & -.03 & $.36^{*}$ & .02 & .05 & 1.0 \\
\hline
\end{tabular}

Notes. $* p<.01 ; \alpha=$ Cronbach's alpha; LT-DMS = Lithuanian Drive for Muscularity Scale, LT-EDEQ-6 = Lithuanian Eating Disorders Examination Questionnaire, LT-SATAQ-4 = Lithuanian Sociocultural Attitudes towards Appearance Questionnaire.

Table 3. Comparisons of the drive for muscularity scores across body mass index and sports groups in Lithuanian male students $(N=763)$

Notes. $M=$ mean, $S D=$ standard deviation, $p=$ level of statistical significance; groups were compared by the independent sample $t$ test.

\begin{tabular}{|l|l|c|c|c|c|}
\hline \multicolumn{2}{|c|}{ Characteristics } & M & SD & F & $\boldsymbol{p}$ \\
\hline \multirow{2}{*}{$\begin{array}{l}\text { Body mass } \\
\text { index }\end{array}$} & Underweight & 2.54 & 1.02 & & \\
\cline { 2 - 4 } & Normal weight & 2.72 & 1.14 & \multirow{2}{*}{1.09} & .338 \\
\cline { 2 - 4 } & Overweight/obesity & 2.60 & 1.17 & & \\
\hline \multirow{2}{*}{$\begin{array}{l}\text { Attending sport } \\
\text { club* }\end{array}$} & No & 2.43 & 1.05 & \multirow{2}{*}{-8.14} & .001 \\
\cline { 2 - 6 } & Yes & 3.12 & 1.16 & & $<$ \\
\hline
\end{tabular}

Table 4. Results of multiple linear regressions predicting disordered eating behaviours in Lithuanian male students $(N=763)$

Notes. $B=$ non standardized regression coefficient, $\beta=$ standardized regression coefficient; $p=$ level of statistical significance. Model summary: $R=0.51 ; R^{2}=0.26 ; F=$ $66.3 ; p<.001$

\begin{tabular}{|l|c|c|c|c|}
\hline \multicolumn{1}{|c|}{ Variables } & $\boldsymbol{B}$ & $\boldsymbol{\beta}$ & $\boldsymbol{t}$ & $\boldsymbol{c}$ \\
\hline Drive for muscularity & 0.071 & 0.097 & 2.834 & .005 \\
\hline Muscular body ideal internalization & 0.193 & 0.240 & 7.097 & $<.001$ \\
\hline Self-esteem & -.028 & -0.194 & -6.127 & $<.001$ \\
\hline Body mass index & 0.086 & 0.372 & 11.877 & $<.001$ \\
\hline
\end{tabular}




\section{DISCUSSION}

The first aim of the present study was to test the psychometric properties of the drive for muscularity scale in the sample of young adults in Lithuania. We expected to replicate the original structure of the scale. Unfortunately, the confirmatory factor analysis did not confirm the suggested 2-factor structure (muscular oriented body attitudes and behaviours) since the model fit indices were poor. Therefore, the use of the general scale is recommended for further analyses. The majority of studies examining the structural validity of this instrument in male samples confirmed a twofactor structure (attitudes subscale and behaviours subscale, Kling et al., 2019). However, studies in women samples did not support the two-factor structure either (de Carvalho, Oliveira, Neves, Meireles, \& Ferreira, 2019). Nevertheless, the Lithuanian drive for muscularity scale demonstrated good internal consistency and test-retest reliability.

Next, we aimed to evaluate the convergent validity of the instrument using measures of BMI, self-esteem, disordered eating behaviours, and internalization of the muscular/athletic body ideal. Based on the previous studies, we expected that the drive for muscularity scale scores would be positively associated with the BMI, internalization of the muscular/athletic body image, disordered eating, and negatively with the self-esteem. This assumption was fully confirmed. The drive for muscularity was positively related to the muscular/athletic ideal internalization and disordered eating, and negatively with self-esteem and body mass index (not significantly). These associations confirm the good convergent validity of the scale. These associations go in line with other studies validating drive for muscularity scale in other cultures (Arellano-Pérez et al., 2019; Gomes et al., 2019; Kling et al., 2019; Sepulveda et al., 2016; Stratton, Donovan, Bramwell, \& Loxton, 2015; Swami et al., 2016).

Finally, we aimed to test the associations between the drive for muscularity and participation in sports. This study demonstrated that students attending sports clubs demonstrated a higher drive for muscularity compared to those not participating in sports. These results mirror the results of other research that provided evidence that participation in some kinds of sports activities (i.e., gyms) are related with the higher drive for muscularity in men (Keum et al., 2015) and participation in moderate physical activity is associated with the greater drive for muscularity in adolescents (Arellano-Pérez et al., 2019). We did not aim to assess the nature of sport participation in the present study; therefore, the generalization of the findings is limited. Future studies should test associations between the drive for muscularity and physical activity. It is recommended to evaluate the nature of sports participation (competitive or leisure exercising), participation in weight-sensitive or less weightsensitive sports, elite and non-elite sports (Lavender et al., 2017). These studies are very important for body image concerns prevention in sport-involved men as well as for the prevention of the disordered eating in physically active men of various ages.

There are some limitations, which should be mentioned. First, the study is cross-sectional, and the directions of the study variables are reciprocal. Second, the generalization of the study is limited to young adults. Future studies are recommended to validate the drive for the muscularity scale in women (de Carvalho et al., 2019) and young adults of different sexual identities. Among the strengths of the study is the solid sample. Further, this study contributes to the growing research on men's body image and adds to the knowledge that drive for muscularity scale is a reliable and valid instrument for the measurement of the drive for muscularity related attitudes and behaviours in a rarely examined linguistic group of Eastern Europe. The studies of men's body image are of great importance in the countries of the rapid westernization. Further, the Lithuanian version of the drive for muscularity scale might be useful for improving clinical practice.

\section{CONCLUSIONS}

The results of the present study support the psychometric properties of the Lithuanian version of the drive for muscularity scale and its use in Lithuanian samples of young men. The instrument might also be used in clinical practice. The drive for muscularity is associated with lower selfesteem, muscular/athletic ideal internalization, and disordered eating. Young men attending sports clubs reported a greater drive for muscularity. It is important to develop prevention programs that decrease body image concerns and prevent disordered eating in young men.

Data availability statement. The data file used for this study is not available publically but is available from the corresponding author under a reasonable request. 


\section{REFERENCES}

Arellano-Pérez, O. G., Vázquez-Cervantes, M. J., Fernández Cortés, T. L., \& Saucedo-Molina, T. (2019). Drive for muscularity and disordered eating behaviors and its relationship with anthropometric indicators and physical activity in Mexican adolescent men. Germany: Springer. doi: 10.1007/s40519-019-00736-2

Baceviciene, M., Balciuniene, V., \& Jankauskiene, R. (2020). Validation of the Lithuanian version of the eating disorder examination questionnaire 6.0 in a student sample. Brain and Behavior, n/a, e01555. doi: 10.1002/ brb3.1555

Baceviciene, M., Jankauskiene, R., \& Balciuniene, V. (2020). Validation of the Lithuanian version of the sociocultural attitudes towards appearance questionnaire-4 (SATAQ-4) in a student sample. International Journal of Environmental Research and Public Health, 17(3), 10.3390/ijerph17030932. doi: E932 [pii]

Bassett-Gunter, R., McEwan, D., \& Kamarhie, A. (2017). Physical activity and body image among men and boys: A meta-analysis. doi: https://doi.org/10.1016/j. bodyim.2017.06.007

Benford, K., \& Swami, V. (2014). Body image and personality among British men: Associations between the big five personality domains, drive for muscularity, and body appreciation. Body Image, 11(4), 454-457. doi: 10.1016/j.bodyim.2014.07.004 [doi]

Bratland-Sanda, S., \& Sundgot-Borgen, J. (2012). Symptoms of eating disorders, drive for muscularity and physical activity among Norwegian adolescents. European Eating Disorders Review: The Journal of the Eating Disorders Association, 20(4), 287-293. doi: 10.1002/erv.1156

Chaba, L., d'Arripe-Longueville, F., LentillonKaestner, V., \& Scoffier-Mériaux, S. (2018). Adaptation and validation of a short French version of the drive for muscularity scale in male athletes (DMS-FR). United States: Public Library of Science. doi: 10.1371/journal. pone. 0196608

Compte, E. J., Sepúlveda, A., R., de Pellegrin, Y., \& Blanco, M. (2015). Confirmatory factor analysis of the drive for muscularity scale-S (DMS-S) and male body attitudes scale-S (MBAS-S) among male university students in Buenos Aires. Netherlands: Elsevier. doi: 10.1016/j.bodyim.2015.02.005

Cruz-Sáez, S., Pascual,A., Salaberria, K., Etxebarria, I., \& Echeburúa, E. (2015). Risky eating behaviors and beliefs among adolescent girls. Journal of Health Psychology, 20(2), 154-163. doi: 10.1177/1359105313500683

DeBlaere, C., \& Brewster, M. E. (2017). A confirmation of the drive for muscularity scale with sexual minority men. Psychology of Sexual Orientation and Gender Diversity, 4(2), 227-232. doi: 10.1037/sgd0000224

de Carvalho, P., Henrique Berbert, Oliveira, F. d. C., Neves, C. M., Meireles, J. F. F., \& Ferreira, M. E. C. (2019). Is the drive for muscularity scale a valid and reliable instrument for young adult women? Netherlands: Elsevier. doi: 10.1016/j.bodyim.2019.02.001

Eik-Nes, T., Austin, S. B., Blashill, A. J., Murray, S. B., \& Calzo, J. P. (2018). Prospective health associations of drive for muscularity in young adult males. United States: Wiley. doi: 10.1002/eat.22943

Escoto, C., Alvarez-Rayón, G., Mancilla-Díaz, J. M., Camacho Ruiz, E. J., Franco Paredes, K., \& Juárez Lugo, C. S. (2013). Psychometric properties of the drive for muscularity scale in Mexican males. Germany: Springer. doi: 10.1007/s40519-013-0010-6

Fairburn, C. G., \& Beglin, S. J. (1994). Assessment of eating disorders: Interview or self-report questionnaire? The International Journal of Eating Disorders, 16(4), 363-370.

Gomes, A. R., Simães, C., Dias, O., Almeida, C., \& Gonçalves, S. (2019). Drive for muscularity and disordered eating behavior in males: The mediating role of cognitive appraisal. Poland: Academy of Physical Education. doi: 10.2478/hukin-2019-0117

Keum, B. T., Wong, S. N., DeBlaere, C., \& Brewster, M. E. (2015). Body image and Asian American men: Examination of the drive for muscularity scale. Psychology of Men \& Masculinity, 16(3), 284-293. doi: 10.1037/a0038180

Kling, J., Kwakkenbos, L., Diedrichs, P. C., Rumsey, N., Frisén, A., Brandão, M. P., Fitzgerald, A. (2019). Systematic review of body image measures. Netherlands: Elsevier. doi: 10.1016/j.bodyim.2019.06.006

Larison, B., \& Pritchard, M. (2019). The effects of internalized shame and self-blame on disordered eating and drive for muscularity in collegiate men. Germany: Springer. doi: 10.1007/s40519-019-00700-0

Lavender, J. M., Brown, T. A., \& Murray, S. B. (2017). Men, muscles, and eating disorders: An overview of traditional and muscularity-oriented disordered eating. Current Psychiatry Reports, 19(6), 32-32. doi: 10.1007/ s11920-017-0787-5

Liu, H., Chang, C., Gill, D. L., Wu, S., \& Lu, F. J. H. (2019). Male weight trainers' body dissatisfaction and exercise dependence: Mediating role of muscularity drive. United States: SAGE. doi: 10.1177/0033294118805010

McCreary, D. R., Sasse, D. K., Saucier, D. M., \& Dorsch, K. D. (2004). Measuring the drive for muscularity: Factorial validity of the drive for muscularity scale in men and women. Psychology of Men \& Masculinity, 5(1), 49-58. doi: 10.1037/1524-9220.5.1.49

McPherson, K. E., McCarthy, P., McCreary, D. R., \& McMillan, S. (2010). Psychometric evaluation of the drive for muscularity scale in a community-based sample of Scottish men participating in an organized sporting event. Netherlands: Elsevier. doi: 10.1016/j. bodyim.2010.06.001

Nerini, A., Matera, C., Baroni, D., \& Stefanile, C. (2016). Drive for muscularity and sexual orientation: 
Psychometric properties of the Italian version of the drive for muscularity scale (DMS) in straight and gay men. Psychology of Men \& Masculinity, 17(2), 137-146. doi: 10.1037/a0039675

Rosenberg, M. (1979). Conceiving the self. New York: Basic Books.

Schaefer, L. M., Burke, N. L., Thompson, J. K., Dedrick, R.F.,Heinberg,L.J., Calogero, R.M.,...Swami, V. (2015). Development and validation of the sociocultural attitudes towards appearance questionnaire-4 (SATAQ-4). Psychological Assessment, 27(1), 54-67. doi: 10.1037/a0037917 [doi]

Sepulveda, A. R., Parks, M., de Pellegrin, Y., Anastasiadou, D., \& Blanco, M. (2016). Validation of the Spanish version of the drive for muscularity scale (DMS) among males: Confirmatory factor analysis. United States: Pergamon. doi: 10.1016/j.eatbeh.2016.01.010

Stratton, R., Donovan, C., Bramwell, S., \& Loxton, N. J. (2015). Don't stop till you get enough: Factors driving men towards muscularity. doi: https://doi.org/10.1016/j. bodyim.2015.07.002

Swami, V., Barron, D., Lau, P. L., \& Jaafar, J. L. (2016). Psychometric properties of the drive for muscularity scale in Malay men. Netherlands: Elsevier. doi: 10.1016/j.bodyim.2016.03.004

Swami, V., Vintila, M., Tudorel, O., Goian, C., \& Barron, D. (2018). Factor structure and psychometric properties of a Romanian translation of the drive for muscularity scale (DMS) in university men. Netherlands: Elsevier. doi: 10.1016/j.bodyim.2018.02.004

Tylka, T. L. (2011). Refinement of the tripartite influence model for men: Dual body image pathways to body change behaviors. Body Image, 8(3), 199-207. doi: 10.1016/j.bodyim.2011.04.008

World Health Organization. (1997). Obesity: Preventing and managing the global epidemic: Report of a WHO consultation on obesity, Geneva, 3-5 June 1997 (no. WHO/NUT/NCD/98.1). Retrieved form https://apps. who.int/iris/handle/10665/63854 